\title{
The Feasibility of Starting Up Business Mobilife: A Medical Company with Mobile Technology
}

\author{
Yulin Shan ${ }^{1, *}$, Yi Chen ${ }^{2}$ \\ ${ }^{I}$ School of business, HuaQiao University of Human Resource Management, Quanzhou, Fujian36200, China \\ ${ }^{2}$ School of mechanical and automotive engineering, South China University of Technology, Guangzhou, Guangdong \\ 510641, China \\ *Corresponding author.Email:alinshan123@qq.com
}

\begin{abstract}
In this paper, two computer engineering students from Span decided to start up a business into the medical treatment industry and enter the global market. The company they would run is called Mobilife Technologies, which is willing to make Alzheimer patients live more easily by launching a software for Alzheimer caring with a series of service and products. To make sure the possibility of the business plan, we make an analysis report, including the external elements analysis and market research. In order to make the company work successfully, some business strategies are formulated as well. Although a few problems exist, it comes a passive conclusion Eventually. It is to succeed in establishment that this paper about, with the exploration of future health caring.
\end{abstract}

Keywords: internet start-up, medical treatment, business analysis

\section{INTRODUCTION}

\section{1background}

Someone in the world develops dementia every 3 seconds. By 2020, more than 50 million people worldwide will be living with Alzheimer's and other forms of dementia. This figure will almost double every 20 years and reach 82 million in 2030 and 152 million in 2050[1]. Alzheimer 's disease is a degenerative brain disease and the most common form of dementia. Dementia should not be considered as a separate disease. This is a general term that describes a group of symptoms. The number of people with this condition doubles every 5 years after the age of 65 Symptoms of the disease first appear after the age of 60, and the risk increases with age.

Leidia Martel and Aarón López joined various research projects at the University Institute of Applied Microelectronics in Las Palmas de Gran Canaria (IUMA), after a noteworthy effort to finish their computer engineering studies. They became terribly hooked in to the thought of making MobiAlz- software for patients with Alzheimer's that they themselves had designed and given because the grand finale of their studies at the University. This software would facilitate patients with Alzheimer's, that could be a scary disease that feeds on the minds of the old and erases their memories.
Officially incorporated in July 2010, Mobilife Technologies was founded as a joint venture between Leidia and an Irish personal friend, who she learned was one of the many forums for entrepreneurs that she frequented. This partnership will not only be the capital, but also in teaching and learning, as well as in-depth knowledge of the English language and culture, to help you with your purchase of the non-Latin American market. In this market, the company's commercial ambitions are necessary if, in the opinion of the North American market, the main focus will be placed on design. There were at least some of their core activities going to be software development for mobile devices.

The company offers 2 varieties of service: client orders, together with maintenance, like the holidaymaker guide and Canadian gathering, and their own telecare service for the development of standard of living and sickness management and interference. This latter service is that the main vocation of the corporation, and a few components of it may be sufficiently competitive to be incorporated in Android ${ }^{\circledR}$ or Apple Store ${ }^{\circledR}$, United Nations agency demand that applications square measure denote by firms instead of universities or analysis institutes, forcing them to get a name to work inside the market. The star merchandise during this cluster square measure MobiAlz that offers support and specific services for Alzheimer's patients, another recent 
development for the management of patients with diabetes, and MobiSync, that permits for speedy development of applications that need synchronization between the net and mobile devices.

\subsection{Significance of subject selection}

At present, the combination of medical and technology is one of the contemporary trends. Mobilife Technologies seizes such an opportunity, but it is in the entrepreneurial period and faces many challenges, such as long time-consuming technology research and development, powerful competitors, etc.

To help such startups find a feasible development strategy has become a major research problem. Combining environmental analysis and industry analysis to propose a feasible business strategy for the company not only provides strategic advice for this company, but also serves as a reference for other companies of the same type.

\section{EXTERNAL ENVIRONMENT ANALYSIS}

\subsection{Environmental factors}

Canary Islands, autonomous community of Spain, are separated into two provinces and each of them includes tens of municipalities.

\subsection{Political factors}

The government of Canary Islands has issued policies and documents that benefit technology innovation enterprises.

The Canary Office of Research, Innovation and Information Society (ACSII) is a government agency. "Promoting and coordinating research, technological development and innovation in the regional universities" "Managing the research, development and innovation promotion programmes" belong to the main objectives of this regional agency. The legal framework in terms of research, technological development and innovation in the Canary Islands is established by the Law 5/2001, of July 9 , concerning the promotion and development of scientific and technical research. It additionally provides a scientific regulation of the activities of the general public authorities within the matter.

\subsection{Economic factors}

The Canary Islands have the best taxation in the European Union with a 4\% Corporate Tax rate [2], this economic policy has created a good living environment for start-ups.

\subsection{Sociocultural Factors}

Demographic ageing is a worldwide process that shows the successes of improved health care over the last century. Dementia primarily affects older individuals, though there is a growing awareness of cases that begin before the age of 65 .

The population of Canaries is regarding 2.15 million inhabitants. According to statistics, the number of over65 s in Canary Islands is 372,232 , almost $17.3 \%$ of total population. The number of over- $65 \mathrm{~s}$ in Canaries is 372,232 ,almost $17.3 \%$ of total population. The number of over-65s with AD in Canaries is 43,557 ,almost $12 \%$ of aged population.

As for health spending, the calculable total worldwide value of dementia was US\$ 818 billion in 2015, that represents $1.09 \%$ of world gross domestic product. The annual international value of dementia is currently above US\$ 1 trillion. According to the investigation, health care pay in the Canary Islands is 2,000(EUR) per person.

\subsection{International factors}

The United States of America, commonly known as the United States or America, is a country primarily located in North America. It consists of 50 states, a federal district, five major unincorporated territories, 326 Indian reservations, and some minor possessions.

The number of Americans living with Alzheimer's is growing - and growing fast. More than 6 million Americans of all ages have Alzheimer's. An estimated 6.2 million Americans age 65 and older are living with Alzheimer's dementia in 2021. This range is projected to just about triple to 14 million individuals by2060[3]. Seventy -two percent are age 75 or older. One in nine people age 65 and older $(11.3 \%)$ has Alzheimer's dementia. Health spending in the U.S. enhanced by $4.6 \%$ in 2019 to $\$ 3.8$ trillion or $\$ 11,582$ per capita [4]

\section{INDUSTRY ANALYSIS}

For both MobiAlz and MobiSync, Software Programmers and developers are their common suppliers. In addition, hospitals, Alzheimer organizations and medical Groups as referral agents for clients and patient, are also suppliers for MobiAlz. Thus, they have a large number of suppliers.

In terms of customers, MobiAlz is a software designed for Alzheimer's patients, thus the patients and their relatives are the main customers of it which is a small and more powerful client base. And for MobiSync small companies that need IT integration are the main customers.

Where close substitute products exist in a market, it increases the likelihood of customers switching to alternatives in response to price increases. Personal care 
is the solely substitute for MobiAlz, including In-home care, residential care, respite care and hospice care, so substitutes pose little threat to MobiAlz. While for MobiSync all of the integration softwares are its substitutes.

Their current competitors are other software companies, not only on the island, but also in many other countries around the world. Apart from this, profitable markets attract new entrants, which erodes profitability. As for new entrant, it is unknown for both MobiAlz and MobiSync, but there are bound to be potential entrant somewhere.

\section{BUSINESS STRATEGY}

\subsection{Lean start-up}

The first thing to consider for a start-up company to take into account is to survive at the beginning. For the Mobilife Technologies, to avoid closing down as possible as it can the necessity to get profit and develop into a competitive transnational internet medical service corporation. As a newly established company, Mobilife Technologies has faced some challenges that can't ignored from the outer factors and the inner drawbacks. In short, the lack of time for technological development and test, which will lead the competitors to catch up, is the biggest one, and the small size of the company with incomplete network with healthcare is the inevitable problem to be complete. So it's necessary to execute the lean star-up strategy.

The lean start-up approach involves releasing a minimal viable product (MVP) to customers with the expectation that this early prototype will change and evolve frequently and quickly in response to customer feedback. You can gain understanding about your customers' interest in your MVP without fully developing the MVP [5]. The sooner you can find out whether your product will appeal to customers, the less effort and expense you spend on a product that will not succeed in the market. It is only then that the actual business can truly emerge.

For Leidia and Aarón, MobiSync, the integration software that handles customer orders, is the MVP of their company. They roll out it as to be the "cash cow" to gain profit and then feed the whole company and strengthen it by the surplus money. During the time MobiSync being on market, they will adjust the functions and details of it by the users' feedback, it is not difficult to operate since it is an internet software. By the time that it got enough fund and information of the target customers, the company would go into the next step, which is to publish the MobiAlz to provide special products and service to the clients.

\subsection{Strategies in the Canary island}

Since the company has just been started in Las Palmas de Canaria, Span, they should focus on the local market during the initial stage, pay attention to the Alzheimer situation in Canary, seek for cooperation with some smartphone or software companies, need help and support from the local medical institutions and the government. In order to go into the North America and even the global market, developing in the start-up place by accumulating fund and reputation is necessary and important.

(1) The first thing to do is to publish the minimal viable product into the matched market. For MobiSync, it is the smart mobile terminal users that directly pay attention to it, and the people with related requirements among them would have the opportunity to become potential customers. So collaborating with the main local smart phone companies or advertising on the smart phone apps to promote the MobiSync is of necessity. In Spain, the leading phone company is MOVISTAR, a large company with preference of large number of smart phone users, and in Canary island, the part of TELEFONICA has $100 \%$ coverage, which means smart phone has large popularity in Canary and many people would know about the MobiSync through their phones.

(2) The company works on the Alzheimer, its target consumers are the diagnosed and potential Alzheimer patients as well as their relatives. It is no doubt that the company should cooperate with the local medical establishments and institutions to advertise and provide product and service to the patients. There are lots of medical establishments in Canary, such as Policlínico Santa Bárbara, Las Palmas de Gran Canaria, San Cristóbal de La Laguna and so on. As the aging of population in Canary, and because of the proportion of getting Alzheimer in old people group, the hospitals will take in more and more Alzheimer patients with the accompany of their family in the future. To satisfy their needs, a series of packages could be released, for example: can be structured as fixed term contracts, month by month or 'pay per event'.

(3) A medically related company has the sense of social responsibility spontaneously, so it is a good choice to establish cooperation with government to offer social benefit to those suffer from Alzheimer, as well as to promote the product by building a beneficent reputation. For instance, providing Alzheimer test for old people or the poor class for free, organizing voluntary activities for Alzheimer patients. On the other hand, asking the governments for political support or subsidy for business is possible. The Canary Islands are formed from two autonomous provinces and each of them includes tens of municipalities. It means that there are more opportunities, lots of autonomous governments to cooperate and the probability of success is greater. 


\section{CONCLUSION}

According to the analysis and market research, there are not few opportunities for the two computer engineers' new establishment of their Mobilife for the Alzheimer. Although facing some challenges and drawbacks, the company would achieve it 's goal eventually if the entrepreneurs get use of the advantage from the external factors and follow the positive strategies they make. So generally speaking, firstly the company needs to find a viable growth strategy regarding both its product lines and current small size, which is the lean start-up strategy. Then it needs to determine the target customer group and target market through further market analysis. Most importantly, the company should develop relationships with the other suppliers and Value Added Resellers to grow the company. After that, it should increase the size and capabilities of R\&D and sales\& marketing departments are important. In the long run, the company may have to leave the MobiSync business behind and turn to focus on MobiAlz, at that time the global market is much closer.

\section{REFERENCES}

[1] Alzheimer's Disease International.(2020)Dementia statistics.

https://www.alzint.org/about/dementia-factsfigures/dementia-statistics/

[2] European Commission.(2021)Canary Islands.

https://ec.europa.eu/growth/tools-

databases/regional-innovation-monitor/base-

profile/canary-islands

[3] Matthews, K. A., Xu, W., Gaglioti, A. H., Holt, J. B., Croft, J. B., Mack, D., \& McGuire, L. C. (2018). Racial and ethnic estimates of Alzheimer's disease and related dementias in the United States (20152060) in adults aged $\geq 65$ years. Alzheimer's \& Dementia.

[4] American Medical Association.(2020)Trends in health care spending.

https://www.ama-assn.org/about/research/trendshealth-care-spending

[5] American Express Company.(2021)Why you should sell a minimum viable product.

https://www.americanexpress.com/enus/business/trends-and-insights/articles/why-youshould-sell-a-minimum-viable-product-1/ 